\title{
Loneliness as a mediator of social relationships and health-related quality of life among refugees living in North Rhine-Westphalia, Germany
}

\author{
Matthias Hans Belau ${ }^{1,2,3^{*}}$, Heiko Becher ${ }^{2}$ and Alexander Kraemer ${ }^{1}$
}

\begin{abstract}
Background: Since 2015, more than one million people fled to Germany - mainly from war-affected countries. Nevertheless, little is known about social determinants in refugees located in Germany. This study aims to test the mediation effect of loneliness between social relationships, comprising social integration and social support, and health-related quality of life among refugees living in North Rhine-Westphalia, Germany.
\end{abstract}

Methods: The investigation utilizes data from the FlueGe Health Study ( $N=326)$, a cross-sectional study conducted by Bielefeld University. The data was collected between February and November 2018 and included interviews and examinations. Participants were recruited from shared and private accommodation in several cities in North RhineWestphalia, Germany. We first analyzed correlations between social integration, social support, loneliness, and physical and mental component of health-related quality of life. We then conducted mediation analyses using structural equation modeling.

Results: The majority of respondents were socially isolated, perceiving a moderate degree of loneliness and social support. In addition, the physical and mental components of health-related quality of life indicate that participants predominantly experienced mental rather than physical impairments. Results from mediation analyses showed indirect effects of loneliness on the association between social integration and mental health ( $B=0.495,95 \%$ bias-corrected and accelerated confidence interval $(\mathrm{BCa} \mathrm{Cl})=[0.018,0.972])$, and between social support and both physical (B $=0.022,95 \% \mathrm{BCaCl}=[0.004,0.040])$ and mental health $(B=0.067,95 \% \mathrm{BCa} C l=[0.037,0.097])$.

Conclusions: Loneliness played a mediating role in the association between social relationships and health-related quality of life among refugees living in North Rhine-Westphalia, Germany. The results provide implications for both, health policy and the host society.

Keywords: Health-related quality of life, Refugees, Social relationships, Loneliness, Mediation

*Correspondence: m.belau@uke.de

${ }^{3}$ University Medical Center Hamburg-Eppendorf, Institute of Medical Biometry and Epidemiology, Martinistraße 52, D-20246 Hamburg, Germany

Full list of author information is available at the end of the article

\section{Background}

In 2015 and 2016, Germany was the main country of asylum for people fleeing from war-affected countries such as Syria, Iraq, Afghanistan, and Central Africa, with 441,900 and 722,400 asylum applications, respectively [1]. Many of them have been subjected to stressful and adverse experiences before, during, and after the flight 
[2]. Experiences of war-related violence and torture in the countries of origin, traumatic events during the journey such as physical assault, extortion, and sexual violence as well as the stressors of the asylum process and poor living conditions in the host country lead to a significant burden of mental illness such as post-traumatic stress disorder (PTSD), depression, and anxiety [3-5]. Concurrently, there are often barriers to receiving medical services and accessing the social system [6, 7]. In Germany, refugees also have limited access to medical care during their asylum process [8]. Therefore, generalized resistance resources [9], including social relationships [10], are needed to deal with those health-related challenges. Literature reveals that social relations have an impact on refugees' health and well-being $[11,12]$. However, many refugees are dealing with loneliness and the experience of loss of friends and family members throughout the migratory journey to Germany [2]. In some cases, family members are left behind to seek asylum in the hope of eventual reunification [2]. The family in particular, as an element of resilience, is assigned a central role in promoting and maintaining health and well-being [13].

Little is known concerning the social relationships of refugees living in Germany and its impact on subjective health parameters such as health-related quality of life (HRQoL). HRQoL captures the personal and social dimensions of a person's well-being and is considered to be a valid, reliable, and robust measure of health status [14] in migrant populations [15]. In addition, HRQoL has been shown to be a significant predictor of health care utilization [16] and mortality [17], underscoring its importance for health policy and public health with respect to refugees. A study focusing on refugee women from war-affected countries resettled in Germany revealed that HRQoL was moderate and significantly worse than that of the European population [18]. Another study assessing HRQoL among refugees in Germany using survey data showed that ethnic groups of refugees (Syrians, Afghans, and Eritreans) differ inherently in their HRQoL [19]. Studies examining the social determinants of refugees' HRQoL during settlement in Germany are lacking. To the best of our knowledge, no study so far aimed to explore the (perceived) health effects of social relationships among refugees resettled in Germany. Literature shows that refugees' family structures vary considerably [20]. The loss of family members and friends seriously affects their loneliness scores. Loneliness, in turn, is a predictor of mental health problems among refugees, such as depression [21].

A theoretical model by Wilson and Cleary [22] considers and describes the influence of the individual and the environment on various dimensions of HRQoL. Social environmental characteristics are the interpersonal or social influences on health and well-being, including the influence of family and friends [23]. Several studies have shown that HRQoL is closely linked with social relationships comprising social networks [24] and social support [25] as an interconnected term. There is evidence that social isolation and lack of social support can lead to loneliness [26]. Few studies postulate an association between lack of social integration and loneliness [27], while loneliness is linked to HRQoL [28]. Thus, the relation between HRQoL and social relationships could be mediated by loneliness. A study assessing the interrelationships among perceived social support, loneliness, and HRQoL [29]showed that loneliness mediates the relationship between social support and HRQoL among South Korean older adults [29], but none in a refugee population.

The goal of our study was to test the mediation effect of loneliness between (indicators of) social relationships, measured on two separate scales as social integration and as social support, and HRQoL among refugees living in North Rhine-Westphalia, Germany. We hypothesized that refugees will develop loneliness in the migration process due to the loss of friends and family members in their country of origin. To test the mediation hypothesis, a recursive model was adopted, and results are based on data from the "FlueGe Health Study" (FHS).

\section{Methods}

\section{Participants and data collection}

The present investigation utilizes data from the FHS, a cross-sectional study administered by the research class "FlueGe - refugee health" at the School of Public Health at Bielefeld University [30]. The FHS aimed to provide health data of refugees from the main countries of origin that contributed to the European refugee crisis in 2015 and 2016 in the region of East Westphalia-Lippe in North Rhine-Westphalia, Germany. The data was collected between February and November 2018 and included personal interviews and physical examinations, carried out by trained interviewers. The interview questionnaire was translated into five languages: Arabic, Farsi, Kurmanji, English, and German. The translation followed the scientific standard [31, 32]. First, certified translators by Kantar Public, a consulting and market research institute, translated the questionnaire from the original version into the remaining languages. Subsequently, other native Arabic, Persian, and Kurdish speakers who were simultaneously fluent in English and German blindly back-translated the translated questionnaire into the original language. The back-translation was done both literally and semantically. Participants were recruited from shared and private accommodation. Municipal cooperation partners and social workers provided access to potential participants. 
The FHS included all participants who were willing to participate, except they were younger than 18 years of age, could not speak Arabic, Kurmanji, Farsi, English, or German, or if they have been in Germany for more than five years. A total of 827 men and women aged 18 to 75 years were assessed for eligibility and invited to the study. Of these, 130 individuals had an inadequate language level, and 371 individuals refused to participate in the FHS. The main reasons were personal reasons as well as having no interest in the research. Overall, 326 men and women signed informed consent and completed the study. Approval from the Ethics Commission of Bielefeld University was obtained before the data was collected to ensure ethical and data protection guidelines.

\section{Measures}

Short Form-12 Health Survey-SOEP (SF-12-SOEP) [33] was used, assessing HRQoL. The information was aggregated into a physical component summary (PCS) and a mental component summary (MCS) score. To compare to published means, both scales were transformed into a range from 0 (minimum) to 100 (maximum), and higher values indicate a better state of health. Furthermore, norm-based scoring was performed by first z-transforming SF-12-SOEP scales using factor loadings on PCS and MCS for weighting served by the SOEP2004 data as the norm population [33] and then transforming them to a mean value of 50 and a standard deviation (SD) of 10 . Cronbach`s alpha of PCS and MCS in the current study were 0.85 and 0.83 , respectively.

Social integration was measured according to the Social Network Index (SNI) [34, 35]. The SNI contains three domains, each scored from 0 to 2: (i) cohabitation with spouse or partner, (ii) contacts with close friends and family, and (iii) affiliation with the religious community and voluntary associations. Cohabitation was scored as 2 if the participant reported living with spouse or partner, and 0 if not. The frequency of contact with close friends and family (face-to-face or by phone, at least once a month) was scored 2 ( $\geq 12$ contacts), 1 (3 to 11 contacts), or 0 ( $<3$ contacts). Affiliation was scored 2 if a participant was a member of a religious group (attending services and activities at least once a month) and member of a group without religious affiliation (sports, community, political, or professional associations common in Germany) or at least member of two groups without religious affiliation. Participants were given a score of 1 if they were a member of a religious group or member of a group without religious affiliation, and a score of 0 , if participants weren't a member of a religious group or a group without religious affiliation. The SNI ranges from 0 to 6 , a score of 0 to 1 indicates strong social isolation (low degree), a score of 2 to 3,4 to 5 , and 6 indicates a moderate, high, and a very high degree of social integration, respectively.

Social support was measured with the Medical Outcomes Study Social Support Survey (MOS-SSS) [36], which consists of four separate subscales (emotional/ informational support, tangible support, affectionate support, positive social interaction) and an overall summary score. To compare to published means, all scales were transformed into a range from 0 (minimum) to 100 (maximum), and higher values indicate a better perception of social support. Cronbach`s alpha of emotional/ informational support, tangible support, affectionate support, positive social interaction, and overall summary score for the present sample was 0.89, 0.92, 0.86, 0.90, and 0.94 , respectively.

The three-item Loneliness Scale-SOEP (LS-SOEP) [37] was used to measure the degree of loneliness. Participants were asked about their agreement on the following questions: (i) "How often do you feel that you lack companionship?", (ii) "How often do you feel left out?", and "How often do you feel isolated from others?" Each question was answered based on a five-level rating scale: Never (0), seldom (1), sometimes (2), often (3), and very often (4). The information was aggregated into a summary score ranging from 0 (minimum) to 12 (maximum) with a higher score indicating stronger feelings of loneliness. Cronbach`s alpha of LS-SOEP in this study was 0.68 .

Sociodemographic information included age, sex, country of origin, and education, which was inquired according to the Comparative Analysis of Social Mobility in Industrial Nations (CASMIN) classification [38]. First, nine educational groups were distinguished, which result from a combination of school and vocational qualifications. Then, the CASMIN index was used to categorize three groups: low (general elementary education and/ or basic vocational qualification), medium (intermediate general qualification and/or intermediate vocational qualification), and high education (lower or higher tertiary education).

\section{Statistical analyses}

Statistical analyses were performed using STATA MP, version 16. Descriptive statistics were used to identify sample characteristics. To test our hypothesis, Spearman correlation and mediation analyses using structural equation modeling (SEM) following causal steps approach by Barron and Kenny [39] and comments by Preacher and Hayes $[40,41]$ were performed. A statistical diagram of the simple mediation model can be found in Fig. 1. In a linear regression model, the health-related quality of life measured as PCS (models 1.1 and 2.1) and MCS score (models 1.2 and 2.2) as metric outcome variables were 


\section{Simple relationship}

Social relationships Health-related quality of life

C

\section{Mediated relationship}

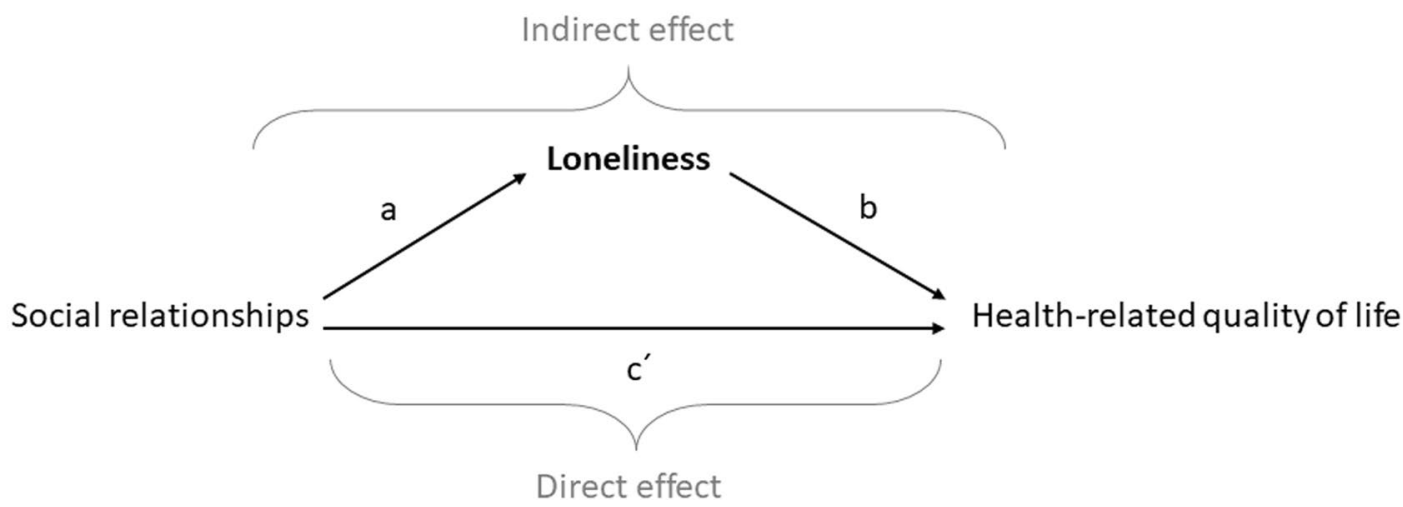

Fig. 1 Simple mediation model of loneliness between social relationships and health-related quality of life

regressed on loneliness (mediator variable) and both social integration (model 1.1 and 1.2) and social support (model 2.1 and 2.2) as predictor variables, respectively. Adjustments were made for age, sex, and education, which were regarded as potential confounders [42]. The adequacy of the structural models was evaluated according to the following model fit criteria: Chi-square statistic/degrees of freedom $\left(x^{2} / \mathrm{df}\right)<3.0$, root mean square error of approximation (RMSEA) $\leq 0.06$, comparative fit index (CFI) $\geq 0.90$, and Tucker-Lewis index (TLI) $\geq 0.90$ [43]. Subjects presenting a missing value for at least one of the modeling variables were excluded from analyses (listwise deletion). We computed 95\% bias-corrected and accelerated (BCa) confidence intervals (CI) from 10,000 bootstrap samples, as it yields accurate $\mathrm{CI}$ for indirect effects [44]. Mediation effects (indirect effect of predictor $X$ on outcome $Y$ through mediator $M$, defined as the product of $a$ ( $X$ on $M$ ) and $b$ ( $M$ on $Y$, controlling for $X)$ ) were considered significant if the $95 \%$ BCa CI does not contain zero.

\section{Results}

Characteristics of the study population $(\mathrm{N}=326)$ are summarized in Table 1 . Men constituted the majority of participants (73.0\%), and the overall median age was 30.0 years. Syrians were the most represented group (40.6\%), followed by Iraqis (24.3\%), Afghans (12.9\%), Africans
(7.1\%), and Iranians (5.9\%). Respondents of African origin came from Algeria (8.7\%), Eritrea (13.0\%), Nigeria (26.1\%), Somalia (17.4\%), Ghana (13.0\%), Guinea (4.4\%), Morocco (8.7\%), and Egypt (8.7\%). More than threefourths of the respondents have been in Germany for more than two years $(76.0 \%), 60.7 \%$ reported a secure (entitlement to asylum, refugee protection, subsidiary protection, and a national ban on deportation), and $39.3 \%$ an insecure residence status (in procedure, temporary suspension of deportation, and a requirement to leave).

The majority of the participants reported a low $(23.0 \%$, men $22.7 \%$, women $23.9 \%$ ) and moderate degree $(46.3 \%$, men $46.2 \%$, women $46.6 \%$ ) of the SNI, indicating social isolation. Only $2.1 \%$ of male participants reported a very high degree of social integration. In addition, participants perceived a moderate degree of loneliness and social support. PCS and MCS scores indicate that participants predominantly experienced mental rather than physical impairments.

Table 2 provided Spearman's correlation coefficients among the variables of interest. The results indicated that social integration was positively related to MCS score $(r=0.276, p<0.001)$. Social support was positively $(\mathrm{r}=0.312, p<0.001)$ and loneliness negatively $(\mathrm{r}=$ -0.442, $p<0.001$ ) correlated to MCS score. Correlations also emerged between MCS score and social support 
Table 1 Characteristics of participants by sex $(\mathrm{N}=326)$

\begin{tabular}{|c|c|c|c|c|c|c|c|}
\hline & & \multicolumn{2}{|c|}{ All participants } & \multicolumn{2}{|l|}{ Male } & \multicolumn{2}{|l|}{ Female } \\
\hline & & $\mathrm{n}$ & $\%$ & $\mathrm{n}$ & $\%$ & $\mathrm{n}$ & $\%$ \\
\hline Age, mean (SD) & & $32.4(11.0)$ & & $31.9(11.2)$ & & $33.8(10.4)$ & \\
\hline Sex & & 326 & 100.0 & 238 & 73.0 & 88 & 27.0 \\
\hline \multirow[t]{7}{*}{ Country of origin } & Syria & 132 & 40.5 & 96 & 40.3 & 36 & 40.9 \\
\hline & Iraq & 79 & 24.2 & 56 & 23.5 & 23 & 26.1 \\
\hline & Afghanistan & 42 & 12.9 & 33 & 13.9 & 9 & 10.2 \\
\hline & Iran & 19 & 5.8 & 14 & 5.9 & 5 & 5.7 \\
\hline & African countries & 23 & 7.1 & 14 & 5.9 & 9 & 10.2 \\
\hline & Other countries & 30 & 9.2 & 24 & 10.1 & 6 & 6.8 \\
\hline & Missing values & 1 & 0.3 & 1 & 0.4 & 0 & 0.0 \\
\hline \multirow[t]{4}{*}{ Education $^{\mathrm{a}}$} & High & 63 & 19.3 & 48 & 20.2 & 15 & 17.1 \\
\hline & Medium & 127 & 39.0 & 97 & 40.8 & 30 & 34.1 \\
\hline & Low & 135 & 41.4 & 93 & 39.1 & 42 & 47.7 \\
\hline & Missing values & 1 & 0.3 & 0 & 0.0 & 1 & 1.1 \\
\hline \multirow[t]{2}{*}{ Social integration, mean (SD) } & Overall summary score & $2.6(1.4)$ & & $2.5(1.4)$ & & $2.6(1.3)$ & \\
\hline & Missing values & 12 & 3.7 & 12 & 5.0 & 0 & 0.0 \\
\hline \multirow[t]{10}{*}{ Social support, mean (SD) } & Overall summary score & $58.4(27.0)$ & & $55.4(27.7)$ & & $66.7(22.9)$ & \\
\hline & Missing values & 21 & 6.4 & 15 & 6.3 & 6 & 6.8 \\
\hline & Emotional, informational support & $55.0(29.5)$ & & $52.3(29.8)$ & & $62.1(27.6)$ & \\
\hline & Missing values & 13 & 4.0 & 10 & 4.2 & 3 & 3.4 \\
\hline & Tangible support & $60.4(37.2)$ & & $58.2(38.2)$ & & $66.5(33.8)$ & \\
\hline & Missing values & 11 & 3.4 & 7 & 2.9 & 4 & 4.6 \\
\hline & Affectionate support & $62.7(35.0)$ & & $57.3(35.6)$ & & $77.5(28.5)$ & \\
\hline & Missing values & 12 & 3.7 & 8 & 3.4 & 4 & 4.6 \\
\hline & Positive social interaction & $60.4(34.3)$ & & $56.8(35.0)$ & & $70.5(30.2)$ & \\
\hline & Missing values & 10 & 3.1 & 6 & 2.5 & 4 & 4.6 \\
\hline \multirow[t]{2}{*}{ Loneliness, mean (SD) } & Overall summary score & $4.5(3.1)$ & & $4.6(3.1)$ & & $4.2(3.0)$ & \\
\hline & Missing values & 11 & 3.4 & 8 & 3.4 & 3 & 3.4 \\
\hline \multirow[t]{4}{*}{ Health-related quality of life, mean (SD) } & Physical component score & $50.8(10.5)$ & & $51.8(10.7)$ & & $48.3(9.5)$ & \\
\hline & Missing values & 17 & 5.2 & 14 & 5.9 & 3 & 3.4 \\
\hline & Mental component score & $43.0(14.5)$ & & $43.3(14.9)$ & & $41.7(13.3)$ & \\
\hline & Missing values & 17 & 5.2 & 14 & 5.9 & 3 & 3.4 \\
\hline
\end{tabular}

a CASMIN classification (26); SD standard deviation; n quantity; \% proportion

subscales (emotional/informational support $(\mathrm{r}=0.197$, $p<0.001)$, tangible support $(\mathrm{r}=0.268, p<0.001)$, affectionate support $(\mathrm{r}=0.282, p<0.001)$ and positive social interaction $(\mathrm{r}=0.321, p<0.001)$ ). In addition, loneliness was negatively associated with social integration ( $\mathrm{r}$ $=-0.162, p=0.007$ ) and social support overall summary score $(\mathrm{r}=-0.394, p<0.001)$ and subscales (emotional/ informational support $(\mathrm{r}=-0.278, p<0.001)$, tangible support $(\mathrm{r}=-0.343, p<0.001)$, affectionate support $(\mathrm{r}$ $=-0.337, p<0.001)$ and positive social interaction $(\mathrm{r}=$ $-0.400, p<0.001)$ ).

To assess mediation, we computed estimates of direct $\left(c^{\prime}\right)$, indirect $(a b)$ and total effects $\left(c=c^{\prime}+a b\right)$ between indicators of social relationships and HRQoL considering loneliness as mediator variable (see Fig. 2). In line with our hypothesis, mediation effects of loneliness between social integration and MCS $(\beta=0.495$, $95 \% \mathrm{BCa} C \mathrm{CI}=[0.018,0.972])$, and social support (overall summary score) and both PCS $(\beta=0.022,95 \% \mathrm{BCa}$ $\mathrm{CI}=[0.004,0.040])$ and MCS score $(B=0.067,95 \%$ $\mathrm{BCa} C \mathrm{CI}=[0.037,0.097])$ were found. Each mediation model showed an acceptable fit (see Fig. 2). Results including the total effects are shown in more detail in the Additional file 3. We also found indirect effects of loneliness between social support subscales and HRQoL. The indirect effect of loneliness on the association between emotional/informational support, tangible support, affectionate support, positive social 
Table 2 Spearman correlation among social integration, social support, loneliness and HRQoL

\begin{tabular}{|c|c|c|c|c|c|}
\hline & 1 & 2 & 3 & 4 & 5 \\
\hline \multicolumn{6}{|l|}{ Social integration } \\
\hline 1 Overall & 1.000 & & & & \\
\hline \multicolumn{6}{|l|}{ Social support } \\
\hline 2 Overall & $0.278^{* * *}$ & 1.000 & & & \\
\hline \multicolumn{6}{|l|}{ Loneliness } \\
\hline 3 Overall & $-0.162^{* *}$ & $-0.394^{* * *}$ & 1.000 & & \\
\hline \multicolumn{6}{|l|}{$\begin{array}{l}\text { Health-related quality } \\
\text { of life }\end{array}$} \\
\hline $\begin{array}{l}4 \text { Physical component } \\
\text { score }\end{array}$ & -0.117 & 0.085 & -0.103 & 1.000 & \\
\hline $\begin{array}{l}5 \text { Mental component } \\
\text { score }\end{array}$ & $0.276^{* * *}$ & $0.312^{* * *}$ & $-0.442^{* * *}$ & -0.032 & 1.000 \\
\hline
\end{tabular}

interaction and PCS score was $\beta=0.018(95 \% \mathrm{BCa}$ $\mathrm{CI}=[0.004,0.031]), \beta=0.014(95 \% \mathrm{BCa} C \mathrm{C}=[0.003$, $0.026]), \beta=0.016(95 \% \mathrm{BCa} C \mathrm{CI}=[0.004,0.028])$ and $\beta$ $=0.016$ (95\% BCa CI $=[0.002,0.030])$, respectively. For MCS score, mediation effects of loneliness were found for emotional/informational support $(B=0.053,95 \%$ $\mathrm{BCa} C \mathrm{CI}=[0.028,0.078])$, tangible support $(\beta=0.044$, $95 \% \mathrm{BCa} C \mathrm{CI}=[0.022,0.067])$, affectionate support $(\AA=$
0.046, 95\% BCa $\mathrm{CI}=[0.022,0.070])$ and positive social interaction $(\beta=0.052,95 \% \mathrm{BCa} C \mathrm{CI}=[0.026,0.079])$.

\section{Discussion}

This study investigated the concurrent effects of structural and functional indicators of social relationships and loneliness on HRQoL and examined the mediating role of loneliness between indicators of social relationships and HRQoL among refugees living in North RhineWestphalia, Germany. The majority of respondents were affected by social isolation, perceiving a moderate degree of loneliness and social support. Our findings indicated that social integration, social support, and loneliness were all correlated with HRQoL. Regression analyses revealed that a lack of both social integration and social support were associated with poorer mental health status, which is consistent with findings of previous studies $[12,45]$. In addition, a lack of social integration and social support were associated with higher levels of loneliness, while loneliness was related to worse physical and mental health. These findings are also consistent with other studies [46, 47]. Concerning mediation analyses, our results suggest that the perception of social support, and to some extent social integration itself, determine the level of loneliness and, through this pathway, influence refugees' HRQoL.

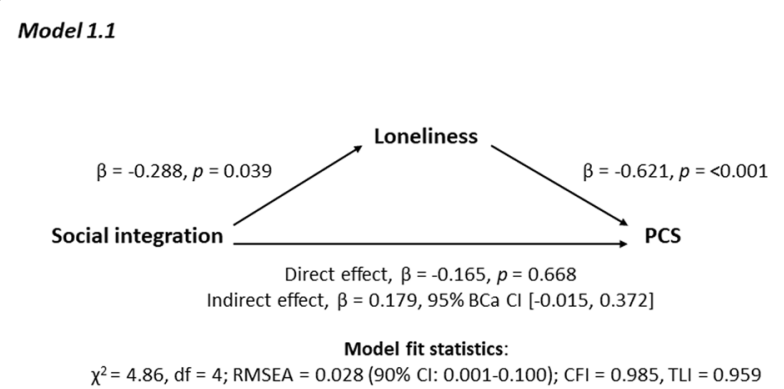

Model 2.1

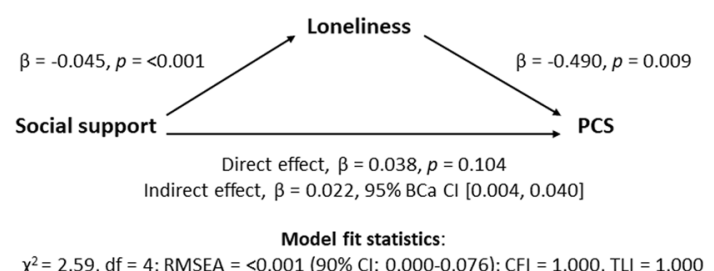

Model 1.2

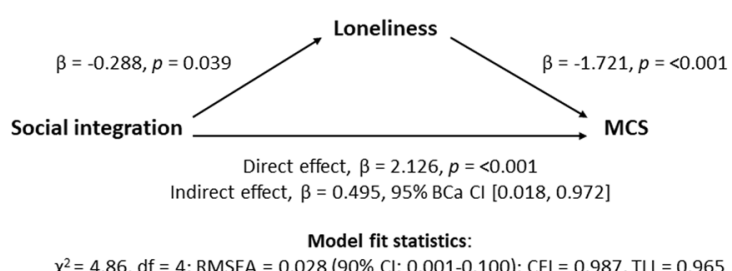

Model 2.2

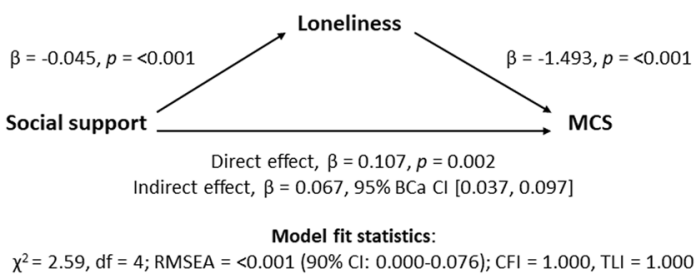

Fig. 2 Models of indicators of social relationships as predictor variables of health-related quality of life, mediated by loneliness, adjusted for age, sex, and education. $\beta$ : regression coefficient; $\mathrm{BCa}$ Cl: bias-corrected and accelerated bootstrapped confidence interval based on 10,000 samples; $\mathrm{Cl}$ : confidence interval; $p$ : $p$-value; $x^{2}$ : Chi-square statistic; df: degrees of freedom; RMSEA: root mean squared error of approximation; CFI: comparative fit index; TLI:Tucker-Lewis index 
Our results corroborate other studies and national surveys that show almost similar patterns of social integration, perceived social support, and loneliness among refugees. A study among refugees in Germany using survey data showed that on average, refugees knew two people (mostly family members and persons from the same country of origin) with whom they could share personal thoughts and feelings [48]. A study assessing perceived social support among Arabic-speaking refugees in Jordan and Germany showed moderate to high social support among respondents [49]. This study also showed that there is a positive effect for mental health issues such as depressive and PTSD symptoms. In previous studies, social integration and having social support are shown to be positively associated with HRQoL [50]. Nevertheless, it should be noted that being alone is not necessarily perceived as painful [51], but a lack of social support often is [52]. A study focusing on physical and mental HRQoL among refugees in Germany showed consistent results, with refugees experiencing mental rather than physical impairments [53]. The study also showed that refugees' physical health was better compared to the general German population, but their mental health was significantly worse, which is consistent with our findings. A study examining loneliness among refugees in Germany found similar levels of loneliness compared to our population studied [54]. Interestingly, the study also shows that refugees in 2020 were about as lonely as they felt in 2016 and 2017. From a public health perspective, these findings show the need for observing how long loneliness persists among refugees resettled in Germany. Further data collection and analysis are needed.

To the best of our knowledge, there is only one study by Kang et al. [29] considering the mediating role of loneliness between perceived social support and HRQoL among South Korean adults. No study so far had examined the mediation effect of loneliness between structural as well as functional indicators of social relationships (social network, social support) and HRQoL among refugees. In our study, an indirect effect of loneliness on the association between perceived social support and PCS score was found. However, a direct effect between perceived social support and PCS score was not detected. As a result, this suggests that perceived social support does not affect physical HRQoL independent of the effect of loneliness on physical HRQoL. Moreover, the indirect effect of perceived social support on both PCS and MCS scores through loneliness was found to be strong, suggesting that a lack of perceived social support promotes the experience of loneliness, which can have a detrimental impact on HRQoL. Thus, loneliness can play a critical role in the relationship between perceived social support and HRQoL among refugees. The results of this study suggest that professionals, policymakers, and the host society must give more attention to the causes of social isolation and loneliness in refugees and continue to invest in family reunification, language education as well as housing and labor market access. These aspects in particular are key factors for the social integration of refugees resettled in Germany and can help decrease loneliness and psychological distress [55].

\section{Limitations}

Our study faces some limitations. We utilized data from the FHS, and selection bias might be an issue especially because participants in the FHS were self-selected. This means that individuals who were not interested in health issues have decided not to participate in the FHS. Moreover, language or health barriers may have hindered participation. Another limitation results from the different language versions of the items used. Particular attention was paid during translation to ensure the correctness of content and language, completeness, comprehensibility, and consistency. Nevertheless, measurement errors can occur [56]. The most widespread Kurdish language, Kurmanji, solely has a large number of different dialects and linguistic peculiarities [57]. Another limitation arise in connection with the cross-sectional design, which restricts the interpretation of the results of the mediation analysis [41]. We adopted a recursive model in which social isolation precedes loneliness and, through this pathway, influences HRQoL. Note that poor health can lead to social isolation and vice versa, e.g., due to confinement in bed or mental disorders such as depression. Therefore, a longitudinal study following the refugees' social relationships, loneliness and HRQoL with time could be elucidating for furthers analysis. Furthermore, other explanations for associations in the mediator model are conceivable: Loneliness as a mediator may only be a correlate to the actual mediator, e.g., socioeconomic living conditions, which are not included in the model. It could also be possible that the mediator considered is influenced by the dependent variable (HRQoL), as other studies $[58,59]$ suggest. Since our data only included a convenience sample of 326 refugees from East-Westphalia-Lippe results cannot be generalized to all refugees in North Rhine-Westphalia and Germany. Finally, it is important to note that further studies need to incorporate more variables, such as socioeconomic status [60] and living conditions [61] that are positively associated with refugees' HRQoL.

\section{Conclusions}

This is the first investigation of testing the mediation effect of loneliness between indicators of social relationships and HRQoL among refugees by using SEM. 
Furthermore, our study provides information on social integration, loneliness, and perceived social support among refugees from war-affected countries after their resettlement in Germany. In conclusion, the majority of respondents were affected by social isolation, perceiving a moderate degree of loneliness and social support. In mediation analyses, loneliness played a mediating role in the association between social integration and MCS as well as perceived social support and PCS as well as MCS score. Together these findings suggest that loneliness can play a critical role in the relationship between perceived social support and HRQoL among refugees. The results of the study provide implications for both, health policy and the host society, respectively. Health policy has to foster refugees' social and economic integration and the host society must be open and inclusive in its orientation towards cultural diversity to reduce loneliness and strengthen social relationships and HRQoL among refugees.

\begin{abstract}
Abbreviations
BCa: bias-corrected and accelerated; CASMIN: Comparative Analysis of Social Mobility in Industrial Nations; Cl: confidence interval; FHS: FlueGe Health Study; HRQoL: health-related quality of life; LS-SOEP: Loneliness Scale-SOEP; MCS: mental component summary; MOS-SSS: Medical Outcomes Study Social Support Survey; PCS: physical component summary; SEM: structural equation modeling; SD: standard deviation; SF-12-SOEP: Short From-12 Health SurveySOEP; SNI: Social Network Index; SOEP: Socio-Economic Panel.
\end{abstract}

\section{Supplementary Information}

The online version contains supplementary material available at https://doi. org/10.1186/s12889-021-12303-5.

Additional file 1: Figure A. Distribution plots of the variables of interest. Additional file 2: Figure B. Two-way scatter plots among variables of interest.

Additional file 3: Table A1. Direct, indirect, and total effects, adjusted for age, sex, and education $(n=268)$.

\section{Acknowledgements}

We acknowledge support regarding data collection provided by the "FlueGe" research consortium and all interviewers. Furthermore, we acknowledge support for the publication costs by the Deutsche Forschungsgemeinschaft and the Open Access Publication Fund of Bielefeld University.

\section{Authors' contributions}

MHB designed the research, conducted the analyses, and wrote the first draft of the manuscript. $\mathrm{HB}$ provided critical input and contributed to the drafting of the manuscript. AK was involved in research design, analysis, and writing. All the authors approved the final manuscript for submission.

\section{Funding}

Open Access funding enabled and organized by Projekt DEAL. The authors did not receive any specific financial support for this research. MHB received funding from the Ministry of Culture and Science of the German State North Rhine-Westphalia (Grant number: 321-8.03.07-127600) in the context of the Research Graduate School on Refugee Health (FlueGe: Fluechtlingsgesundheit) comprising five faculties of Bielfeld University. AK was Senior Professor at Bielefeld University's School of Public Health and Director of the Graduate Research Programm FlueGe. The funding source played no role in the design of the study; the collection, analysis, and interpretation of the data; or the writing of this article.

\section{Availability of data and materials}

The data that support the findings of this study are available from Bielefeld University, but restrictions apply to the availability of these data, which were used under license for the current study, and so are not publicly available. Data are however available from the corresponding author (Matthias Belau/email: m.belau@uke.de) upon reasonable request and with permission of Bielefeld University.

\section{Declarations}

\section{Ethics approval}

This study was performed in line with the principles of the Declaration of Helsinki. Approval was granted by the Ethics Committee of Bielefeld University (23. December 2017/2017-072W). Every participant signed an informed consent to participate.

\section{Competing interests}

The authors declare that they have no competing interests.

\section{Author details}

${ }^{1}$ School of Public Health, Bielefeld University, Bielefeld, Germany. ${ }^{2}$ Institute of Medical Biometry and Epidemiology, University Medical Center HamburgEppendorf, Hamburg, Germany. ${ }^{3}$ University Medical Center HamburgEppendorf, Institute of Medical Biometry and Epidemiology, Martinistraße 52, D-20246 Hamburg, Germany.

Received: 17 February 2021 Accepted: 19 November 2021

Published online: 08 December 2021

\section{References}

1. United Nations High Commissioner for Refugees (UNHCR). Gobal Trends: Forced Displacement in 2017. 2018. https://www.unhcr.org/5b27be547. pdf. Accessed 10 Feb 2021.

2. Brücker H, Rother N, Schupp J. IAB-BAMF-SOEP Survey of Refugees: Overview and first Results. 2016. https://www.bamf.de/SharedDocs/Anlagen/ DE/Forschung/Forschungsberichte/fb29-iab-bamf-soep-befragung-geflu echtete.pdf?_blob=publicationFile\&v=15. Accessed 10 Feb 2021.

3. Biddle L, Menold N, Bentner M, Nöst S, Jahn R, Ziegler S, Bozorgmehr K. Health monitoring among asylum seekers and refugees: a state-wide, cross-sectional, population-based study in Germany. Emerg Themes Epidemiol. 2019; doi:https://doi.org/10.1186/s12982-019-0085-2.

4. Nesterko Y, Jäckle D, Friedrich M, Holzapfel L, Glaesmer H. Health care needs among recently arrived refugees in Germany: a cross-sectional, epidemiological study. Int J Public Health. 2020; doi:https://doi.org/10. 1007/s00038-020-01408-0.

5. Lindert J, von Ehrenstein OS, Wehrwein A, Brähler E, Schäfer I. Anxiety, Depression and Posttraumatic Stress Disorder in Refugees - A Systematic Review. Psychother Psychosom Med Psychol. 2018; doi:https://doi.org/10. 1055/s-0043-103344.

6. Wetzke M, Happle C, Vakilzadeh A, Ernst D, Sogkas G, Schmidt RE, Behrens GMN, Dopfer C, Jablonka A. Healthcare Utilization in a Large Cohort of Asylum Seekers Entering Western Europe in 2015. Int J Environ Res Public Health. 2018; doi:https://doi.org/10.3390/ijerph15102163.

7. Butenop J, Pruskil S, Grünberger E. Future Challenges for the Public and Curative Health Sector. In: Kraemer A, Fischer F, editors. Refugee Migration and Health: Challenges for Germany and Europe. Cham: Springer; 2019. p. 119-32.

8. Bozorgmehr K, Wenner J, Razum O. Restricted access to health care for asylum-seekers: applying a human rights lens to the argument of resource constraints. Eur J Public Health. 2017; doi:https://doi.org/10. 1093/eurpub/ckx086.

9. Antonovsky A. Unraveling the mystery of health: How people manage stress and stay well. San Francisco: Jossey-Bass; 1987.

10. Berkman LF. The role of social relations in health promotion. Psychosom Med. 1995; doi:https://doi.org/10.1097/00006842-199505000-00006. 
11. Georgiadou E, Schmitt GM, Erim Y. Does the separation from marital partners of Syrian refugees with a residence permit in Germany have an impact on their quality of life? J Psychosom Res. 2020; doi:https://doi.org/ 10.1016/j.jpsychores.2020.109936.

12. Al-Smadi AM, Tawalbeh LI, Gammoh OS, Ashour AF, Alshraifeen A Gougazeh YM. Anxiety, stress, and quality of life among Iraqi refugees in Jordan: A cross sectional survey. Nurs Health Sci. 2017; doi:https://doi. org/10.1111/nhs.12323.

13. Stainton A, Chisholm K, Kaiser N, Rosen M, Upthegrove R, Ruhrmann S, Wood SJ. Resilience as a multimodal dynamic process. Early Interv Psychiatry. 2019; doi:https://doi.org/10.1111/eip.12726.

14. Bullinger M, Quitmann J. Quality of life as patient-reported outcomes: principles of assessment. Dialogues Clin Neurosci. 2014; doi:https://doi. org/10.31887/DCNS.2014.16.2/mbullinger.

15. Buchcik J, Westenhoefer J, Martin CR. Assessment measures of HealthRelated Quality of Life (HRQoL) of migrants: a systematic review. International Journal of Migration, Health and Social Care. 2013; doi:https://doi. org/10.1108/IJMHSC-09-2013-0033.

16. Hajek A, Kretzler B, König HH. Determinants of Frequent Attendance in Primary Care. A Systematic Review of Longitudinal Studies. Front Med (Lausanne). 2021; doi:https://doi.org/10.3389/fmed.2021.595674.

17. Phyo AZZ, Freak-Poli R, Craig H, Gasevic D, Stocks NP, Gonzalez-Chica DA, Ryan J. Quality of life and mortality in the general population: a systematic review and meta-analysis. BMC Public Health. 2020; doi:https://doi. org/10.1186/s12889-020-09639-9.

18. Jesuthasan J, Sönmez E, Abels I, Kurmeyer C, Gutermann J, Kimbel R, Krüger A, Niklewski G, Richter K, Stangier U et al. Near-death experiences, attacks by family members, and absence of health care in their home countries affect the quality of life of refugee women in Germany: a multi-region, cross-sectional, gender-sensitive study. BMC Med. 2018; doi:https://doi.org/10.1186/s12916-017-1003-5.

19. Grochtdreis T, König H-H, Riedel-Heller SG, Dams J. Health-Related Quality of Life of Asylum Seekers and Refugees in Germany: a CrossSectional Study with Data from the German Socio-Economic Panel. Applied Research in Quality of Life. 2020; doi:https://doi.org/10.1007/ s11482-020-09877-4.

20. Brücker H, Croisier J, Kosyakova Y, Kröger H, Pietrantuono G, Rother N, Schupp J. Second wave of the IAB-BAMF-SOEP Survey: Language skills and employment rate of refugees improving with time. 2019. http:// doku.iab.de/kurzber/2019/kb0319_englisch.pdf. Accessed 4 Oct 2021.

21. Nutsch $N$, Bozorgmehr K. The effect of postmigration stressors on the prevalence of depressive symptoms among refugees in Germany. Analysis of the IAB-BAMF-SOEP Survey 2016. Bundesgesundheitsblatt Gesundheitsforschung Gesundheitsschutz. 2020; doi:https://doi.org/10. 1007/s00103-020-03238-0.

22. Wilson IB, Cleary PD. Linking clinical variables with health-related quality of life. A conceptual model of patient outcomes. Jama. 1995;273:59-65.

23. McLeroy KR, Bibeau D, Steckler A, Glanz K. An ecological perspective on health promotion programs. Health Educ Q. 1988; doi:https://doi.org/10. 1177/109019818801500401

24. Becker T, Leese M, Clarkson P, Taylor RE, Turner D, Kleckham J, Thornicroft G. Links between social network and quality of life: an epidemiologically representative study of psychotic patients in south London. Soc Psychiatry Psychiatr Epidemiol. 1998; doi:https://doi.org/10.1007/s001270050 058.

25. Salinero-Fort M, Gómez-Campelo P, Bragado-Alvárez C, AbánadesHerranz JC, Jiménez-García R, de Burgos-Lunar C. Health-related quality of life of latin-american immigrants and spanish-born attended in spanish primary health care: socio-demographic and psychosocial factors. PLoS One. 2015; doi:https://doi.org/10.1371/journal.pone. 0122318.

26. Peplau LA, Perlman D. Loneliness: A sourcebook of current theory, research and therapy. New York: Wiley; 1982.

27. Keith PM, Braito R, Breci M. Rethinking isolation among the married and the unmarried. Am J Orthopsychiatry. 1990; doi:https://doi.org/10.1037/ h0079167.

28. Jakobsson U, Hallberg IR. Loneliness, fear, and quality of life among elderly in Sweden: a gender perspective. Aging Clin Exp Res. 2005; doi:https://doi.org/10.1007/bf03327417.

29. Kang HW, Park M, Wallace Hernandez JP. The impact of perceived social support, loneliness, and physical activity on quality of life in South Korean older adults. J Sport Health Sci. 2018; doi:https://doi.org/10.1016/j.jshs. 2016.05.003.

30. Bielefeld University. FlueGe Health Study. https://www.uni-bielefeld.de/ (en)/fluege/gesundheitsstudie/ (2018). Accessed 10 Feb 2021.

31. Flaherty JA, Gaviria FM, Pathak D, Mitchell T, Wintrob R, Richman JA, Birz S. Developing instruments for cross-cultural psychiatric research. J Nerv Ment Dis. 1988;176:257-63.

32. van Ommeren M, Sharma B, Thapa S, Makaju R, Prasain D, Bhattarai R, de Jong J. Preparing Instruments for Transcultural Research: Use of the Translation Monitoring Form with Nepali-Speaking Bhutanese Refugees. Transcultural Psychiatry. 1999; doi:https://doi.org/10.1177/1363461599 03600304.

33. Andersen HH, Mühlbacher A, Nübling M, Schupp J, Wagner CG. Computation of standard values for physical and mental health scale scores using the SOEP version of SF-12v2. Schmollers Jahrbuch. 2007;127:171-182.

34. Berkman LF, Syme SL. Social networks, host resistance, and mortality: a nine-year follow-up study of Alameda County residents. Am J Epidemiol. 1979; doi:https://doi.org/10.1093/oxfordjournals.aje.a112674.

35. Berkman LF, Melchior M, Chastang JF, Niedhammer I, Leclerc A, Goldberg M. Social integration and mortality: a prospective study of French employees of Electricity of France-Gas of France: the GAZEL Cohort. Am J Epidemiol. 2004; doi:https://doi.org/10.1093/aje/kwh020.

36. Sherbourne CD, Stewart AL. The MOS social support survey. Soc Sci Med. 1991; doi:https://doi.org/10.1016/0277-9536(91)90150-b.

37. Luhmann M, Schupp J. Loneliness Scale-SOEP. In: Kemper CJ, Brähler E, Zenger M, editors. Psychologische und sozialwissenschaftliche Kurzskalen: Standardisierte Erhebungsinstrumente für Wissenschaft und Praxis. Berlin: Medizinisch Wissenschaftliche Verlagsgesellschaft; 2014 p. 192-3.

38. Brauns H, Steinmann S. Educational Reform in France, West-Germany, and the United Kingdom. Updating the CASMIN Educational Classification. ZUMA-Nachrichten. 1999:44:7-44.

39. Baron RM, Kenny DA. The moderator-mediator variable distinction in social psychological research: conceptual, strategic, and statistical considerations. J Pers Soc Psychol. 1986; doi:https://doi.org/10.1037//0022-3514. 51.6.1173.

40. Preacher KJ, Hayes AF. SPSS and SAS procedures for estimating indirect effects in simple mediation models. Behav Res Methods Instrum Comput. 2004; doi:https://doi.org/10.3758/bf03206553.

41. Hayes AF. Causal Steps, Confouding, and Causal Order. In: Hayes AF, editor. Introduction to Mediation, Moderation, and Conditional Process Analysis: Methodology in the Social Sciences. New York: The Guilford Press; 2018. p. 113-46.

42. Pearce N, Greenland S. Confounding and Interaction. In: Ahrens W, Pigeot I, editors. Handbook of Epidemiology. New York: Springer; 2014. p. 659-84.

43. Hu Lt, Bentler PM. Cutoff criteria for fit indexes in covariance structure analysis: Conventional criteria versus new alternatives. Structural Equation Modeling: A Multidisciplinary Journal. 1999; doi:https://doi.org/10. 1080/10705519909540118.

44. Mackinnon DP, Lockwood CM, Williams J. Confidence Limits for the Indirect Effect: Distribution of the Product and Resampling Methods. Multivariate Behav Res. 2004; doi:https://doi.org/10.1207/s15327906m br3901_4.

45. Miller A, Hess JM, Bybee D, Goodkind JR. Understanding the mental health consequences of family separation for refugees: Implications for policy and practice. Am J Orthopsychiatry. 2018; doi:https://doi.org/10. 1037/ort0000272.

46. Stewart M, Simich L, Shizha E, Makumbe K, Makwarimba E. Supporting African refugees in Canada: insights from a support intervention. Health Soc Care Community. 2012; doi:https://doi.org/10.1111/j.1365-2524.2012. 01069.x.

47. Gleeson C, Frost R, Sherwood L, Shevlin M, Hyland P, Halpin R, Murphy J, Silove D. Post-migration factors and mental health outcomes in asylumseeking and refugee populations: a systematic review. Eur J Psychotraumatol. 2020; doi:https://doi.org/10.1080/20008198.2020.1793567.

48. Siegert M. Social Contacts of Refugees. Edition 04|2019 of the Brief Analyses of the Migration, Integration and Asylum Research Centre at the Federal Office for Migration and Refugees. 2019. https://www. bamf.de/SharedDocs/Anlagen/EN/Forschung/Kurzanalysen/kurzanalys 
e4-2019_iab-bamf-soep-befragung-soziale-kontakte-gefluechtete.pdf; jsessionid=DA26685ED37EDFDA73BB6DE269E1AD1B.intranet382? blob=publicationFile\&v=6. Accessed 7 Oct 2021.

49. Böge K, Karnouk C, Hahn E, Demir Z, Bajbouj M. On Perceived Stress and Social Support: Depressive, Anxiety and Trauma-Related Symptoms in Arabic-Speaking Refugees in Jordan and Germany. Front Public Health. 2020; doi:https://doi.org/10.3389/fpubh.2020.00239.

50. van der Boor CF, Amos R, Nevitt S, Dowrick C, White RA-O. Systematic review of factors associated with quality of life of asylum seekers and refugees in high-income countries. Confl Health. 2020; doi:https://doi. org/10.1186/s13031-020-00292-y

51. Peplau LA, Perlman D. Perspectives on loneliness. In: Peplau LA, Perlman $D$, editors. Loneliness: A sourcebook of current theory, research and therapy. New York: Wiley; 1982. p. 1-20.

52. Barrera MJ. Social support research in community psychology. In: Rappaport J, Seidman E, editors. Handbook of Community Psychology. New York: Kluwer Academic/Plenum Publishers; 2000. p. 215-45.

53. Metzing M, Schacht $D$, Scherz A. Mental and physical health of refugees compared to other populations. 2020. https://www.diw.de/documents/ publikationen/73/diw 01.c.703996.de/20-5-1.pdf. Accessed 7 Oct 2021.

54. Entringer T, Jacobsen J, Kröger H, Metzing M. Refugees' mental health during the coronavirus pandemic: psychological distress and continued loneliness. 2021. https://www.diw.de/documents/publikationen/73/diw_ 01.c.813983.de/dwr-21-12-1.pdf. Accessed 7 Oct 2021.

55. Walther L, Kröger H, Tibubos AN, Ta TMT, von Scheve C, Schupp J, Hahn E, Bajbouj M. Psychological distress among refugees in Germany: a crosssectional analysis of individual and contextual risk factors and potential consequences for integration using a nationally representative survey. BMJ Open. 2020; doi:https://doi.org/10.1136/bmjopen-2019-033658.

56. Biemer PP, Groves RM, Lyberg L, Mathiowetz NA, Sudman S. Measurement errors in survey. New York: Wiley; 1991

57. MacKenzie DN. Kurdish dialect studies. London: Oxford University Press; 1962.

58. Fees BS, Martin P, Poon LW. A model of loneliness in older adults. J Gerontol B Psychol Sci Soc Sci. 1999; doi:https://doi.org/10.1093/geronb/54b.4. p231.

59. Jung FU, Luck-Sikorski C. Overweight and Lonely? A Representative Study on Loneliness in Obese People and Its Determinants. Obes Facts. 2019; doi:https://doi.org/10.1159/000500095.

60. Abdo N, Sweidan F, Batieha A. Quality-of-life among Syrian refugees residing outside camps in Jordan relative to Jordanians and other countries. PeerJ. 2019; doi:https://doi.org/10.7717/peeri.6454.

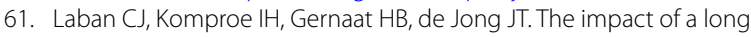
asylum procedure on quality of life, disability and physical health in Iraqi asylum seekers in the Netherlands. Soc Psychiatry Psychiatr Epidemiol. 2008; doi:https://doi.org/10.1007/s00127-008-0333-1.

\section{Publisher's Note}

Springer Nature remains neutral with regard to jurisdictional claims in published maps and institutional affiliations.

Ready to submit your research? Choose BMC and benefit from:

- fast, convenient online submission

- thorough peer review by experienced researchers in your field

- rapid publication on acceptance

- support for research data, including large and complex data types

- gold Open Access which fosters wider collaboration and increased citations

- maximum visibility for your research: over $100 \mathrm{M}$ website views per year

At BMC, research is always in progress.

Learn more biomedcentral.com/submissions 